\title{
Correlations between angiogenic factors and capillaroscopic patterns in systemic sclerosis
}

\author{
Jérôme Avouac ${ }^{1,2}$, Maeva Vallucci ${ }^{2}$, Vanessa Smith ${ }^{3}$, Patricia Senet ${ }^{4}$, Barbara Ruiz ${ }^{2}$, Alberto Sulli ${ }^{5}$, Carmen Pizzorni ${ }^{5}$, \\ Camille Frances ${ }^{4}$, Gilles Chiocchia ${ }^{2}$, Maurizio Cutolo ${ }^{5}$ and Yannick Allanore ${ }^{1,2^{*}}$
}

\begin{abstract}
Introduction: We sought to assess whether nailfold videocapillaroscopy (NVC) patterns are associated with levels of angiogenic factors in systemic sclerosis (SSC).

Methods: Circulating endothelial progenitor cells (EPCs) and circulating endothelial cells (CECs) were measured in the peripheral blood of 60 consecutive SSc patients. Serum levels of eight endothelial markers were measured first in these 60 patients, and then in an independent replication cohort of 43 SSC patients in case of association with NVC patterns. NVC patterns were determined by four independent investigators blinded to vascular markers.

Results: Patients with the late-NVC pattern exhibited lower EPC levels $(P<0.0001)$ and higher VEGF levels $(P=$ 0.03). Higher VEGF levels were confirmed to be associated with the late-NVC pattern in the replication cohort $(P=$ 0.01). By multivariate analysis focused on biomarkers, lower EPC $(P=0.03)$ and higher VEGF levels $(P=0.001)$ were independently associated with the late-NVC pattern. In an alternate multivariate model including these two factors and SSc-related disease characteristics, lower EPC counts $(P=0.005)$, higher VEGF levels $(P=0.01)$, a history of digital ulcers $(P=0.04)$, and a modified Rodnan skin score $>14(P<0.0001)$ were independently associated with the late-NVC pattern.

Conclusion: Our data revealed decreased EPC counts and increased VEGF levels in patients with the late-NVC pattern. Further studies are now needed to determine the role of VEGF and EPCs in endothelial injury and repair in SSC.
\end{abstract}

\section{Introduction}

Systemic sclerosis (SSc) is a severe connective tissue disease characterized by vascular, immune, and fibrotic changes in the skin and some internal organs [1]. Early and diffuse microvascular alterations are key features of SSc, with outcome depending on the extent and severity of vascular lesions. The earliest clinical symptoms of SSc relate to disturbances in the peripheral vascular system. Moreover, work with animal models showed that endothelial cell apoptosis could be a primary event in the pathogenesis of SSc [2-6]. Endothelial cell injury results in disorganization of endothelial layer favoring early impaired capillary architecture and loss of capillaries [7]. These features can be detected on nailfold videocapillaroscopy (NVC), which shows a variety of

\footnotetext{
* Correspondence: yannick.allanore@cch.aphp.fr

'Rheumatology A department, Paris Descartes University, Sorbonne Paris

Cité, Cochin Hospital, rue du Faubourg Saint Jacques, 27, Paris, 75014, France Full list of author information is available at the end of the article
}

morphologic changes including enlarged capillaries, bushy capillary formations, microhemorrhages, and a variable loss of capillaries with or without avascular areas $[8,9]$ from the very early stages. In accordance, $\mathrm{NVC}$ is used as a marker in early and even preclinical stages of SSc [10]. This decreased capillary density, insufficiently compensated by endothelial repair processes, which relate to angiogenesis and vasculogenesis, results in blood flow being insufficient and reduction of oxygen supply that leads to tissue hypoxia. These phenomena are often accompanied by abnormal levels of angiogenic/angiostatic factors and markers of endothelial cell injury, as well as disturbed vasculogenesis with abnormal numbers of circulating endothelial progenitor cells (EPCs) [11-17]. In addition, several vascular markers, including circulating EPCs, placenta growth factor

C Biomed Central

(c) 2013 Avouac et al.; licensee BioMed Central Ltd. This is an open access article distributed under the terms of the Creative Commons Attribution License (http://creativecommons.org/licenses/by/2.0), which permits unrestricted use, distribution, and reproduction in any medium, provided the original work is properly cited. 
(PIGF) and soluble vascular cell-adhesion molecule (sVCAM) have been recently shown to predict the occurrence of ischemic digital ulcers and cardiovascular events, complications that directly relate to microvascular complications [18].

Thus, we hypothesized that microvascular abnormalities with disturbed capillary architecture objectified on NVC could be related to an impairment of selective factors reflecting disturbances of angiogenesis, endothelium damage, and vasculogenesis. To test this hypothesis, we assessed whether NVC changes were associated with peripheral blood or serum levels of endothelial factors in SSc.

\section{Materials and methods Patient sets}

Two different cohorts were used in this study. All patients gave informed consent for all procedures, which were carried out with local ethics committee approval (Comité de Consultation pour la Protection des Personnes se prêtant à la Recherche Biomédicale (CCPPRB) ParisCochin).

\section{Discovery cohort}

The first patient set consisted on consecutive patients with SSc referred to the Rheumatology A Department over a 6month period for systematic follow-up. Eligible patients were those who had been on a stable treatment regimen for at least 3 months, including vasodilators (calcium channel blockers, angiotensin-converting enzyme inhibitors, endothelin-receptor antagonists, PDE5 inhibitors) and immunosuppressive drugs (methotrexate, azathioprine, and prednisone dosage $\leq 10 \mathrm{mg} /$ day). No patient was treated with cyclophosphamide or prostacyclins at the time of this study.

\section{Clinical assessments}

We systematically collected the following data: age, disease duration (date of the first non-Raynaud symptom), duration of Raynaud phenomenon, cutaneous subset according to the criteria reported by LeRoy et al. [19], skin involvement according to the modified Rodnan skin score (mRSS) [20], digital ulceration (past or current), and treatment received.

\section{Routine laboratory assessments}

Routine laboratory studies obtained on the morning of hospital admission included complete blood cell count, Westergren erythrocyte sedimentation rate (ESR), C-reactive protein (CRP) level, serum creatinine concentration, levels of proteinuria and von Willebrand factor antigen (ELISA, VIDAS von Willebrand; BioMérieux, Marcy l'Etoile, France), and tests for anticentromere (immunofluorescence on Hep2 cells) and antitopoisomerase-I antibodies (counter immunoelectrophoresis).

\section{Pulmonary and cardiac assessments}

Echocardiography was performed by a senior cardiologist according to the American Society of Echocardiography recommendations. In particular, left ventricular ejection fraction (LVEF) was determined by using the Simpson method, and systolic PAP (sPAP) was based on the tricuspid and/or pulmonary regurgitation, adding 10 $\mathrm{mm} \mathrm{Hg}$ for auricular pressure. Pulmonary hypertension was suspected at baseline or during follow-up based on (a) an estimated echocardiographic systolic pulmonary arterial pressure (sPAP) $>40 \mathrm{~mm} \mathrm{Hg}$, Or (b) a DLCO < $50 \%$ predicted in absence of pulmonary fibrosis; or (c) unexplained dyspnea, as previously published $[21,22]$ and had to be confirmed by RHC as a resting mean pulmonary artery pressure $\geq 25 \mathrm{~mm} \mathrm{Hg}$ together with a pulmonary capillary wedge pressure of $\leq 15 \mathrm{~mm} \mathrm{Hg}$ (precapillary $\mathrm{PH}$ ).

Pulmonary involvement was assessed with chest radiograph, computed tomography, and measurement of forced vital capacity (FVC) and the diffusing capacity for carbon monoxide/alveolar volume (DLCO/AV) ratio.

\section{Replication cohort}

This second patient set consisted on patients with SSc recruited during a patient meeting (business meeting of the Association des Sclérodermiques de France, Strasbourg, 27 April, 2012). Age, disease duration, and cutaneous subset according to the criteria reported by LeRoy et al. [19] were collected for all the patients, together with the main clinical complications and ongoing medications.

\section{Nailfold videocapillaroscopy}

NVC was performed for all patients of the two cohorts. Patients were asked not to smoke and take caffeinated drinks for at least 4 hours before $\mathrm{NVC}$, and to remain at least 15 minutes at $22^{\circ} \mathrm{C}$ to $23^{\circ} \mathrm{C}$ before NVC.

\section{Collection and blinding of the NVC images}

The nailfolds of the second, third, fourth, and fifth fingers were examined bilaterally in each patient by two independent investigators blinded for the serum status of SSc patients (discovery cohort: JA, replication cohort: JA and PS), by using an optical probe videocapillaroscope equipped with a $\times 200$ magnification contact lens and connected to image-analysis software (Videocaps, DS MediGroup, Milan, Italy). Four consecutive fields extending over $1 \mathrm{~mm}$, in the middle of the nailfold, were studied per finger $[23,24]$. The images were made anonymous before being assessed by four independent investigators (VS, AS, CP, MC), blinded for the clinical and serum status of SSc patients.

\section{Qualitative assessment of NVC images}

The following NVC definitions were used for the qualitative assessment of the NVC patterns. 
The early NVC scleroderma pattern: the combination of few enlarged/giant capillaries, few capillary microhemorrhages, a relatively well-preserved capillary distribution, and no evident loss of capillaries.

The active NVC scleroderma pattern: frequent giant capillaries, frequent capillary microhemorrhages, moderate loss of capillaries, mild disorganization of the capillary architecture, and absent or mild ramified capillaries.

The late-NVC scleroderma pattern: irregular enlargement of the capillaries, few or absent giant capillaries and microhemorrhages, severe loss of capillaries with large avascular areas, disorganization of the normal capillary array, and ramified/bushy capillaries (7). The Additional File 3 shows representative pictures of these three NVC patterns.

EPC and CEC cell sorting and flow-cytometry quantification EPC and CEC quantification were performed only in the discovery cohort. Quantification of EPCs and CECs was precluded in the replication cohort because this procedure required fresh blood samples, and the patient meeting was organized in another city than the one where our laboratory is located. As used in previous reports, 20-ml samples of heparinized venous blood were taken at rest from the forearm, in the morning, at the same time as samples collected from hospitalized patients for routine analysis [15]. Samples were immediately transported to the laboratory for testing. We used a method previously described and validated to enrich mononuclear cells and quantify EPCs and CECs $[15,18,25]$. Negative lineage (Lin-) mononuclear cells were obtained by enrichment from 20-ml peripheral blood mononuclear cells by using $1,000 \mathrm{ml}$ of a human progenitor cell enrichment cocktail (RosetteSep; StemCell Technologies, Vancouver, BC, Canada). The enriched mononuclear cells were collected by Ficoll density gradient centrifugation (Pancoll; Dutcher, Brumath, France), and then washed and preincubated for 15 minutes with $100 \mathrm{ml}$ of an FcR blocking reagent (Miltenyi Biotec, Paris, France) to inhibit nonspecific binding or specific binding via Fc receptors. These cells were then subjected to triple labeling for EPC or CEC detection, according to recent recommendations and previous publications [15]. For EPC detection, $10 \mathrm{ml}$ of enriched mononuclear cells was labeled with $5 \mathrm{ml}$ of each anti-CD133-phycoerythrin (PE, Miltenyi Biotec) and anti-CD34-fluorescein isothiocyanate (FITC; BD Bioscience, Le Pont de Claix, France) antibodies, and 20 ml of anti-VEGFR-2 (KDR)-allophycocyanin (APC; R\&D Systems, Minneapolis, MN, USA) antibodies. For CEC detection, $10 \mathrm{ml}$ of enriched mononuclear cells was labeled with $5 \mathrm{ml}$ each of anti-CD133-PE and antiCD105-FITC (AbD Serotec, Colmar, France) and $20 \mathrm{ml}$ of anti-VEGFR-2-APC. Five milliliters of 7AAD (BD Bioscience) were used for real-time viability staining to identify dead cells 20 minutes before flow cytometry.
Control cells were also prepared by incubation with fluorescence-labeled isotype-matched monoclonal antibodies (Beckman Coulter, Villepinte, France). The labeled cells were analyzed by using a fluorescence-activated cell sorter (FACS; four-color flow cytometry with a FACS Calibur flow cytometer (BD Bioscience). A large number of events $(500,000)$ was considered for every sample. The same detector sensitivity, compensation setting, and scatter-gate set were used to analyze all samples. Viable cells were identified by gating on forward/side scatters and as the 7AAD-population. The expression of CD133 and VEGFR-2 by gated viable CD $34^{+}$cells was assessed. The EPC and CEC populations were identified as $\mathrm{Lin}^{-} /$ $7 \mathrm{AAD}^{-} / \mathrm{CD} 133^{+} / \mathrm{CD}^{+} 4^{+} / \mathrm{VEGFR}-2^{+}$, and $\mathrm{Lin}^{-} / 7 \mathrm{AAD}^{-} /$ CD $133^{-} / \mathrm{CD} 105^{+} / \mathrm{VEGFR}-2^{+}$cells, respectively. Data were analyzed with FlowJo software (Version 7.6.5). Results were expressed as the number of EPCs per million Linmononuclear cells.

\section{Serum levels of endothelial markers}

Serum was isolated from the peripheral blood of all patients included in the discovery and replication cohorts. In the replication cohort, sera was also taken at rest from the forearm, in the morning, and stored locally before shipment to our laboratory, in the days after the patient meeting. Serum levels of eight endothelial factors that have been shown to be implicated in SSc (VEGF, placenta growth factor (PIGF), sVCAM, angiopoietin-2, endoglin, endostatin, endothelin-1 and Tie-2) were measured by using the quantitative sandwich enzyme-linked immunosorbent assay (ELISA) technique (Quantikine kits; R\&D systems) [11-14,17,18,26-28]. No patient in our cohort had regular alcohol consumption, which has been reported to have an important influence on serum levels of VEGF. Concentrations were calculated by using a standard curve generated with specific standards provided by the manufacturer. The analytic range, and intraassay and interassay coefficients of variation are detailed for each marker in Additional File 1. Serum levels of these eight endothelial markers were first assessed in the discovery cohort. Only serum levels of endothelial markers that were found associated with NVC patterns in the discovery cohort were measured in the replication cohort.

\section{Statistical analysis}

All data are presented as median (range) for continuous variables and numbers and percentages for categoric variables, unless stated otherwise. The $\chi^{2}$ test was used to compare categoric variables. In that case, patients with early and active NVC patterns were merged and further compared with patients with the late-NVC pattern. Comparisons between the three NVC patterns were by a nonparametric Kruskal-Wallis test. A multiple linear regression analysis was also performed for all variables 
identified with $P \leq 0.1$ univariately. $P$ values $<0.05$ were considered significant.

\section{Results \\ Study population}

The discovery cohort consisted of 60 consecutive SSc patients (46 women, 77\%), with a median (range) age of 53.5 years (28 to 81 years) and median (range) disease duration of 9 years ( 1 to 50 years). Thirty-six (60\%) patients had the diffuse cutaneous subset, and 24, the limited. Their baseline characteristics are shown in Table 1.

The replication cohort consisted on 43 patients with SSc (33 women, 77\%), with a median (range) age of 57 years (34 to 80 years) and median (range) disease duration of 7 years (1 to 29 years). Fifteen (35\%) patients had the diffuse cutaneous subset, and 28 , the limited.

\section{Qualitative capillaroscopic assessment}

Fourteen (23\%) patients had an early-, 22 (37\%), an active-, and 24 (40\%), a late-NVC SSc pattern in the discovery cohort. In the replication cohort, eight (19\%) patients had an early-, 20 (46\%) an active-, and 15 (35\%) a late-NVC pattern.

\section{Levels of endothelial factors}

To assess the validity of flow cytometry and ELISA measurements, we compared the levels of endothelial markers observed in SSc patients with the values obtained in a population of 20 healthy age- and sex-matched controls $[15,29]$. EPC levels were significantly higher than those of controls, in agreement with our previous results [15], and CEC levels were significantly decreased in SSc patients (see Additional file 2). Serum levels of VEGF, PlGF, endostatin, endothelin-1, and angiopoietin-2 were significantly higher in SSc patients; and no difference was observed with controls for sVCAM, endoglin, and Tie-2 serum levels (Additional file 2).

\section{Levels of endothelial factors and NVC patterns}

In univariate analysis focused on vascular factors, patients from the discovery cohort and with the lateNVC pattern exhibited significantly lower EPC levels than did patients with early and active patterns (median EPC levels, $31 / 10^{6}$ Lin-mononuclear cells in the lateNVC pattern versus 61 and $82 / 10^{6}$ Lin-mononuclear cells in the early- and active-NVC patterns, respectively; $P<0.0001$ ) (Table 2 and Figure 1A, B).

In the discovery cohort, higher VEGF serum levels were observed in the late-NVC pattern (median VEGF serum levels, $814 \mathrm{pg} / \mathrm{ml})$, as compared with the early- $(518 \mathrm{pg} /$ $\mathrm{ml})$ and active- $(493 \mathrm{pg} / \mathrm{ml}) \mathrm{NVC}$ patterns $(P=0.01)$ (Table 2 and Figure 1C, D). This result was confirmed in the replication cohort (median VEGF levels in the lateNVC pattern: $708 \mathrm{pg} / \mathrm{ml}$ versus $445 \mathrm{pg} / \mathrm{ml}$ in patients with the early- or active-NVC pattern; $P=0.01$ ) (Figure 2A), and in the combined population of 103 patients (median VEGF levels in the late-NVC pattern: $770 \mathrm{pg} / \mathrm{ml}$ versus $483 \mathrm{pg} / \mathrm{ml}$ in patients with the early- or active-NVC pattern; $P=0.003$ ) (Figure 2B).

Endothelin-1 serum levels were significantly higher in the active pattern $(2.5 \mathrm{pg} / \mathrm{ml})$ compared with the early and late patterns ( 1.5 and $1.7 \mathrm{pg} / \mathrm{ml} ; P=0.02$ ) in the discovery cohort (Table 2). This result was not confirmed in the replication cohort (median endothelin-1 levels in the active NVC pattern: $2.9 \mathrm{pg} / \mathrm{ml}$ versus $2.1 \mathrm{pg} / \mathrm{ml}$ in patients with the early-NVC pattern and $3.2 \mathrm{pg} / \mathrm{ml}$ in patients with the late-NVC pattern; $P=0.2$ ), or in the combined cohort.

No association was observed between the levels of other serum markers and NVC patterns in the discovery cohort (Table 2).

Table 1 Characteristics of the 60 patients with systemic sclerosis included in the discovery cohort

\begin{tabular}{ll}
\hline Age (years), median (range) & $53.5(28-81)$ \\
Disease duration (years), median (range) & $9(1-50)$ \\
Limited/Diffuse cutaneous subset, $n(\%)$ & $36(60) / 24(40)$ \\
Modified Rodnan skin score $>14, n(\%)$ & $19(32)$ \\
History of digital ulcers, $n(\%)$ & $29(47)$ \\
Pulmonary fibrosis on CT scan, $n(\%)$ & $28(47)$ \\
Pulmonary arterial hypertension on RHC, $n(\%)$ & $4(7)$ \\
Positive antinuclear antibodies (> 1/160), $n(\%)$ & $53(88)$ \\
Positive antitopoisomerase-1 antibodies, $n(\%)$ & $28(47)$ \\
Positive anticentromere antibodies, $n(\%)$ & $12(20)$ \\
FVC $<75 \%$ predicted, $n$ (\%) & $13(22)$ \\
DLCO/AV $<75 \%$ predicted, $n$ (\%) & $23(38)$ \\
Treatment with calcium channel blockers, $n$ (\%) & $60(100)$ \\
Treatment with angiotensin-converting enzyme inhibitors, $n$ (\%) & $19(32)$ \\
Treatment with endothelin-receptor antagonists and/or PDE5 inhibitors, $n(\%)$ & $12(20)$
\end{tabular}

DLCO/AV, diffusing capacity for carbon monoxide/alveolar volume; FVC, forced vital capacity; PDE5, phosphodiesterase type 5; RHC, right heart catheterization. 
Table 2 Nailfold videocapillaroscopy patterns and endothelial marker levels in peripheral blood or serum of patients with systemic sclerosis included in the discovery cohort

\begin{tabular}{|c|c|c|c|c|}
\hline & \multicolumn{3}{|c|}{ Capillaroscopy pattern } & \multirow[t]{2}{*}{$P$ value } \\
\hline & $\begin{array}{l}\text { Early } \\
\text { Median (range) }\end{array}$ & $\begin{array}{l}\text { Active } \\
\text { Median (range) }\end{array}$ & $\begin{array}{l}\text { Late } \\
\text { Median (range) }\end{array}$ & \\
\hline EPCs (10 $0^{6}$ Lin-mononuclear cells) & $61(29-573)$ & $82(21-300)$ & $31(5-300)$ & $<0.0001$ \\
\hline CECs ( $10^{6}$ Lin-mononuclear cells) & $81(10-342)$ & $36(5-155)$ & $77(6-472)$ & 0.4 \\
\hline VEGF $(\mathrm{pg} / \mathrm{ml})$ & $518(161-1,028)$ & $493(156-1,146)$ & $814(189-1,564)$ & 0.01 \\
\hline PIGF (pg/ml) & $9.6(4.6-24.2)$ & $9.9(0.7-19.6)$ & $10.5(2.3-26.5)$ & 0.8 \\
\hline sVCAM-1 (ng/ml) & $766(482-1,828)$ & $694(354-1,405)$ & $767(459-1,314)$ & 0.4 \\
\hline Tie-2 (ng/ml) & $24.4(12.9-29.4)$ & $21.1(14.1-27.1)$ & $22.2(16-39.6)$ & 0.3 \\
\hline Endostatin (ng/ml) & $185(88-477)$ & $139(54-178)$ & $150(22-662)$ & 0.3 \\
\hline Endoglin (CD105) (ng/ml) & $3.7(1.9-5.0)$ & $3.9(2.8-5.6)$ & $3.5(2.6-5.1)$ & 0.5 \\
\hline Endothelin-1 (pg/ml) & $1.5(1.0-3.6)$ & $2.5(0.9-7.2)$ & $1.7(0.4-3.1)$ & 0.02 \\
\hline Angiopoietin-2 (pg/ml) & $2,166(1241-3,312)$ & $2,016(1,249-4,027)$ & $2202(1,512-5,148)$ & 0.5 \\
\hline von Willebrand factor antigen (\%) & $180(95-266)$ & $169(69-304)$ & $170(83-302)$ & 0.9 \\
\hline
\end{tabular}

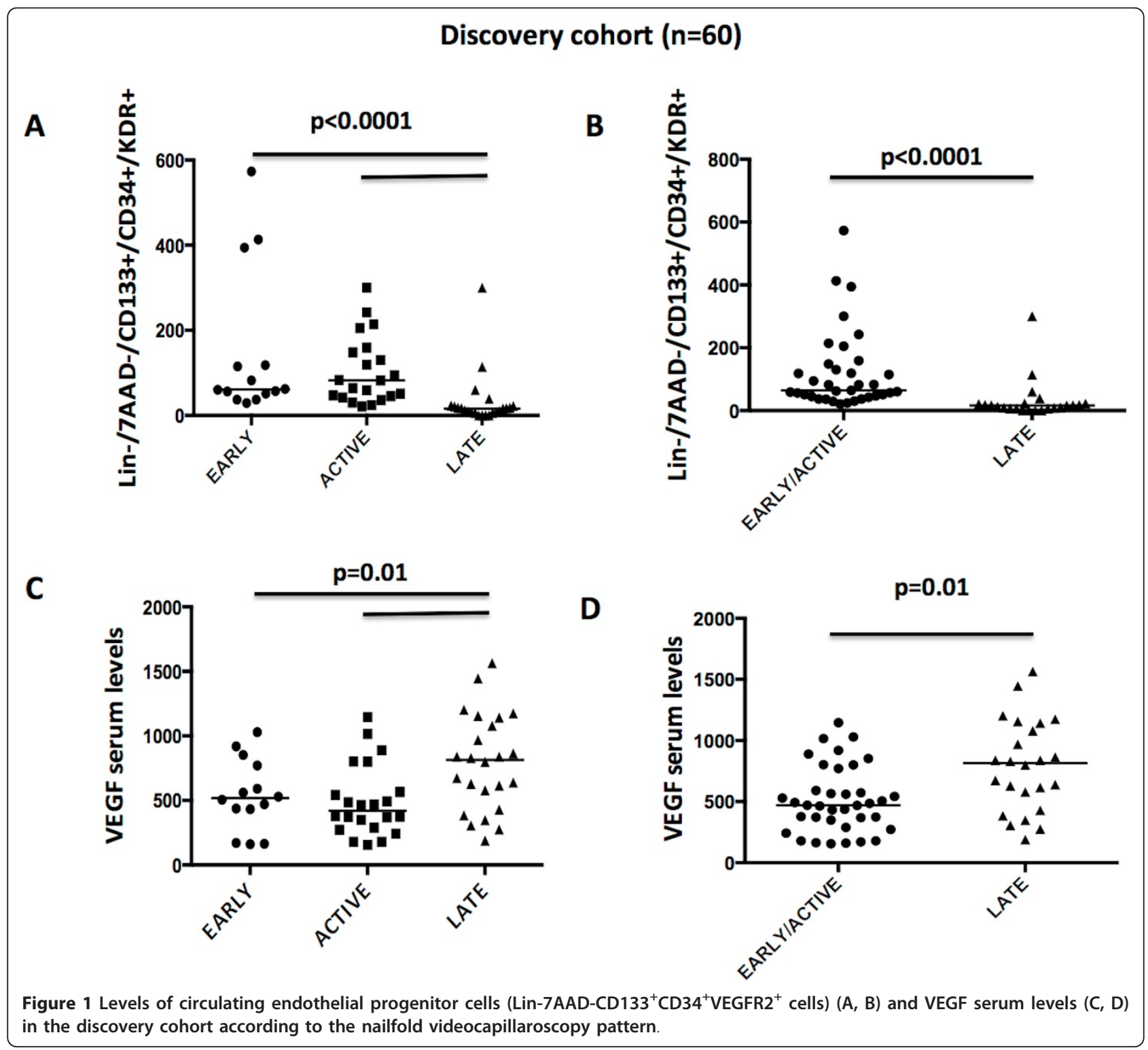




\section{Replication cohort $(n=43)$}

A

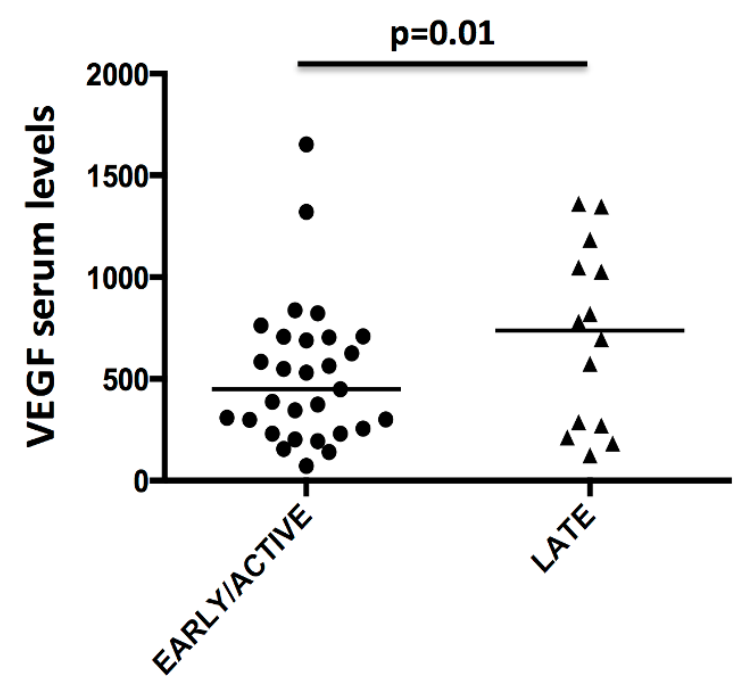

Combined cohort $(n=103)$

B

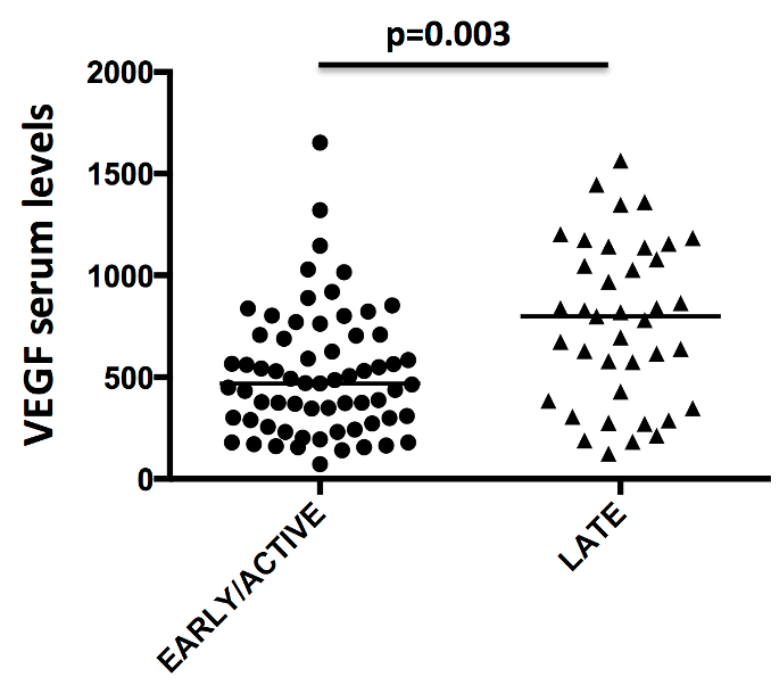

Figure 2 Serum VEGF levels in the replication cohort (A), and combined cohort (B), according to the nailfold videocapillaroscopy pattern.

In multivariable analysis performed with multiple linear regression, including EPC counts, VEGF serum levels, and endothelin serum levels, only EPC counts $(r=-0.41 ; P=$ $0.003)$ and VEGF serum levels $(r=0.36 ; P=0.001)$ were independently associated with the late-NVC pattern.

SSc disease characteristics and NVC patterns in the discovery cohort

The $\chi^{2}$ analysis performed revealed several associations between the late-NVC pattern and SSc-related disease characteristics (Table 3). Patients with the late-NVC pattern were more likely to have an mRSS > 14 (13 of 24, $54 \%$, versus six of $36,17 \% ; P=0.005)$ and a history of digital ulcers ( 16 of $24,67 \%$, versus 13 of $36,36 \%$; $P=0.03$ ) than patients with the early- or the active-NVC pattern. In addition, the likelihood of positive antitopoisomerase-I antibodies (16 of $24,67 \%$, versus 12 of $36,33 \% ; P=0.02$ ) and decreased DLCO/AV $<75 \%$ (14 of $24,58 \%$, versus nine of $36,25 \% ; P=0.02$ ) was significantly higher in patients with the late-NVC pattern.

In multiple linear regression analysis performed for all variables identified with $P \leq 0.10$ univariately, an mRSS > 14 ( $r=0.42 ; P=0.0008)$, history of digital ulcers $(r=0.25$; $P=0.03)$, and an FVC $<75 \%(r=0.29 ; P=0.01)$ were independently associated with the late-NVC pattern (Table 3 ).

Angiogenic factors, SSc disease characteristics, and NVC patterns

We next tested an alternate multiple linear regression model including both angiogenic markers independently associated with the late-NVC pattern (circulating EPCs and VEGF serum levels) and SSc-related disease characteristics associated univariately with $P \leq 0.10$ with the late-NVC pattern.

In this model, lower EPC counts $(r=-0.45 ; P=0.005)$ and higher VEGF levels $(r=0.37 ; P=0.01)$ remained independently associated with the late-NVC pattern, together with a modified Rodnan skin (mRSS) score $>14(r=0.50$; $P<0.0001)$ and history of digital ulcerations $(r=0.25 ; P=$ 0.04) (Table 4).

\section{Discussion}

This is the first study to show decreased EPC counts and increased VEGF serum levels in patients with the late-NVC pattern.

Reduced EPC numbers in the late-NVC pattern suggest that deficient vasculogenesis may contribute to the severe loss of capillaries observed in this pattern. Indeed, decreased EPC numbers can lead to insufficient endothelial repair and depressed new blood vessels formation that could be related to the extensive areas of desertification. Decreased EPC levels in this stage may be consistent with decreased mobilization from the bone marrow, as suggested in a previous study [30]. In the latter study, the stromal compartment of SSc bone marrow was defective in functional EPCs, particularly in patients with late-phase disease. Decreased EPC levels in the peripheral blood of patients with the late-NVC pattern could also be related to an increased EPC homing. Several studies previously reported that EPCs might be recruited at injured sites 
Table 3 Association between nailfold videocapillaroscopy patterns and disease characteristics of patients with systemic sclerosis included in the discovery cohort

\begin{tabular}{|c|c|c|c|c|c|}
\hline & \multicolumn{2}{|l|}{ NVC pattern } & \multirow[t]{2}{*}{$P$ value } & \multirow{2}{*}{$\begin{array}{l}\text { Multiple linear regression } \\
(r)\end{array}$} & \multirow[t]{2}{*}{$P$ value } \\
\hline & $\begin{array}{l}\text { Early/active } \\
(n=36)\end{array}$ & $\begin{array}{l}\text { Late } \\
(n=24)\end{array}$ & & & \\
\hline Age, median (range) & 58 & 53 & 0.2 & & \\
\hline Females, $n(\%)$ & $27(75)$ & 19 & 0.9 & & \\
\hline Disease duration, median (range) & 9.91 & 7.20 & 0.2 & & \\
\hline Diffuse cutaneous subset, $n$ (\%) & $13(36)$ & $11(46)$ & 0.9 & & \\
\hline Modified Rodnan skin score > $14, n(\%)$ & $6(17)$ & $13(54)$ & $0.005^{*}$ & 0.42 & 0.0008 \\
\hline History of digital ulcers, $n(\%)$ & $13(36)$ & $16(67)$ & $0.03^{*}$ & 0.25 & 0.03 \\
\hline Pulmonary fibrosis, $n$ (\%) & $15(42)$ & $13(54)$ & 0.5 & & \\
\hline Pulmonary arterial hypertension on $\mathrm{RHC}, n(\%)$ & $2(6)$ & $2(8)$ & 0.9 & & \\
\hline Positive antitopoisomerase antibodies, $n$ (\%) & $12(33)$ & $16(67)$ & $0.02^{*}$ & & \\
\hline Positive anticentromere antibodies, $n(\%)$ & $9(25)$ & $3(13)$ & 0.4 & & \\
\hline $\mathrm{FVC}<75, n(\%)$ & $5(14)$ & $8(33)$ & $0.1^{*}$ & 0.29 & 0.01 \\
\hline DLCONA < 75\%, n (\%) & $9(25)$ & $14(58)$ & $0.02^{*}$ & & \\
\hline $\begin{array}{l}\text { Treatment with angiotensin-converting enzyme } \\
\text { inhibitors, } n(\%)\end{array}$ & $8(22)$ & $11(46)$ & $0.09^{*}$ & & \\
\hline $\begin{array}{l}\text { Treatment with endothelin-receptor antagonists and/or } \\
\text { PDE5 inhibitors, } n(\%)\end{array}$ & $4(11)$ & $8(33)$ & $0.08^{*}$ & & \\
\hline
\end{tabular}

$\mathrm{DLCO} / \mathrm{AV}$, diffusing capacity for carbon monoxide/alveolar volume; FVC, forced vital capacity; NVC, nailfold videocapillaroscopy; PDE5, phosphodiesterase type 5; $\mathrm{RHC}$, right heart catheterization. * Variables included in multiple regression analysis

during active vascular and severe disease [15,31,32]. These data support overall insufficient vasculogenesis to counterbalance vascular damage and might suggest the mobilization of EPCs from the bone marrow (for example, with administration of G-CSF, statins, or erythropoietin) as a potential target for future therapies in SSc, especially in patients with the late-NVC pattern [33-35].
The severe capillary loss observed in the late-NVC pattern might also be related to decreased angiogenesis. This insufficient angiogenesis might be related to decreased levels of proangiogenic factors. However, we detected in two independent and homogeneous cohorts increased VEGF serum levels in SSc patients with the lateNVC pattern, compared with patients with the early- or

Table 4 Alternate multiple linear regression model performed in the discovery cohort and including both angiogenic factors independently associated with the late-NVC pattern and SSc-related disease characteristics associated univariately with $P \leq 0.10$ with the late-NVC pattern

\begin{tabular}{|c|c|c|c|c|c|}
\hline & \multicolumn{2}{|l|}{ NVC pattern } & \multirow[t]{2}{*}{$P$ value } & \multirow{2}{*}{$\begin{array}{l}\text { Multiple } \\
\text { linear } \\
\text { regression } \\
(r)\end{array}$} & \multirow[t]{2}{*}{$P$ value } \\
\hline & $\begin{array}{l}\text { Early/Active } \\
(n=36)\end{array}$ & $\begin{array}{l}\text { Late } \\
(n=24)\end{array}$ & & & \\
\hline Modified Rodnan skin score $>14, n(\%)$ & $6(17)$ & $13(54)$ & $0.005^{*}$ & 0.50 & $<0.0001$ \\
\hline History of digital ulcers, $n$ (\%) & $13(36)$ & $16(67)$ & $0.03^{*}$ & 0.25 & 0.04 \\
\hline Positive antitopoisomerase antibodies, $n(\%)$ & $12(33)$ & $16(67)$ & $0.02^{*}$ & & \\
\hline $\mathrm{FVC}<75, n(\%)$ & $5(14)$ & $8(33)$ & $0.1^{*}$ & & \\
\hline DLCONA $<75 \%, n(\%)$ & $9(25)$ & $14(58)$ & $0.02^{*}$ & & \\
\hline Treatment with angiotensin-converting enzyme inhibitors, $n$ (\%) & $8(22)$ & $11(46)$ & $0.09^{*}$ & & \\
\hline Treatment with endothelin-receptor antagonists and/or PDE5 inhibitors, $n(\%)$ & $4(11)$ & $8(33)$ & $0.08^{*}$ & & \\
\hline EPCs ( $10^{6}$ Lin-mononuclear cells), median (range) & $64(21-573)$ & $31(5-300)$ & $<0.0001^{*}$ & -0.45 & 0.005 \\
\hline VEGF (pg/ml), median (range) & $470(156-1,146)$ & $814(189-1,564)$ & $0.01^{*}$ & 0.37 & 0.01 \\
\hline
\end{tabular}

DLCO/AV, diffusing capacity for carbon monoxide/alveolar volume; FVC, forced vital capacity; NVC, nailfold videocapillaroscopy. ${ }^{*}$ Variables included in multiple regression analysis 
active-NVC pattern. Thus, VEGF upregulation may appear as an insufficient compensatory mechanism to stimulate angiogenesis. In addition, the observation of lower EPC counts in the late-NVC pattern also supports that vasculogenesis is not sufficiently compensated by VEGF upregulation. This result is in accordance with those of other research groups that found significantly higher VEGF levels in the late stages of the disease, as compared with the levels in patients with recent onset [12,31]. Moreover, an inverse correlation between serum VFGF levels and capillary density has been reported [32,36]. The same findings have been observed in systemic lupus erythematosus: significantly higher VEGF serum levels have been detected in patients with decreased capillary density and neoangiogenesis ( $>75 \%$ morphologically changed loops, as tortuous, enlarged, and/or disarranged capillaries) [37]. In addition, a prolonged overexpression of VEGF may have deleterious effects on the vascular network, because it may result in a chaotic vascular morphology with reduced blood flow in the newly formed vessels. A chronic and uncontrolled overexpression of VEGF does occur in SSc and might significantly be implicated in the altered vessel morphology observed in the late-NVC pattern [38].

We did not find any differential concentration of other proangiogenic markers (PIGF, angiopoietin-2, and Tie-2) between the different NVC patterns. One recent previous study identified a trend for higher angiopoietin-2 levels in patients with the late-NVC pattern with respect to those with an early/active pattern [17]. This discrepancy may be explained by the characteristics of the study populations (lower proportion of patients with the diffuse cutaneous subset and higher disease duration in our study) and by the measurement of angiopoietin- 2 in the serum in our study, versus plasma in the other study. The insufficient angiogenesis observed in the lateNVC pattern might also be related to increased levels of angiostatic factors, which have been reported to be predominant in the late stages of SSc. However, we did not observe increased levels of endostatin and endoglin, two major inhibitors of angiogenesis. Further evaluation of other angiostatic markers should be assessed to confirm these findings.

We also determined whether SSc-disease characteristics might be associated with NVC patterns. No association was noted between the late-NVC pattern and disease duration, which supports that patients with early disease may experience severe vascular loss not sufficiently compensated by new-vessel formation. We found that the lateNVC pattern was associated in univariate analysis with more-severe vascular manifestations (history of digital ulcers) or with the presence of markers of a more-diffuse SSc subset (mRSS $>14$ and antitopoisomerase-I antibodies). Multivariate analysis confirmed the independent association between the late-NVC pattern and the following characteristics: history of digital ulcers, mRSS $>14$, and an FVC $<75 \%$ of predicted; which support a moresevere and fibrotic propensity of the late-NVC pattern. These results are consistent with previously published data, which showed that patients with the late-NVC pattern have an increased risk to experience digital ulcers, more-severe skin thickening, and decreased FVC and DLCO, compared with patients with early and active patterns [39]. In addition, an mRSS $>14$ remained independently associated with the late-NVC pattern after the inclusion of the endothelial markers in the statistical model. These results support the more severe and fibrotic propensity of the late-NVC pattern.

Our study has several limitations that deserve consideration. Our study is limited by its observational design, and any pathogenic link emerging from this type of study should be taken very cautiously. Our sample size was too limited to assess adequately disease phenotype associations in specific subsets of patients, especially those with confirmed pulmonary arterial hypertension, or those with active digital ulcers. In addition, our NVC assessment was only qualitative, based on pattern recognition. Next to associations between endothelial factors and qualitative NVC assessment, efforts should be further made to find associations with quantitative assessment, based on counting of hallmark parameters of the SSc pattern. Now quantitative assessment has to find a definite place in research settings and also in daily practice. Thus, further evaluation of endothelial markers with some recently proposed quantitative index/scores might be performed to confirm our findings obtained with pattern recognition [40-42].

\section{Conclusions}

Our data revealed decreased EPC counts and VEGF upregulation in patients with the late-NVC pattern. Further studies are now needed to determine the respective role of EPCs and VEGF in endothelial injury and endothelial repair in SSc.

\section{Additional material}

Additional file 1: Table S1. Analytic range, and intraassay and interassay coefficients of variation of the quantitative sandwich enzyme-linked immunosorbent assay for each endothelial marker.

Additional file 2: Table S2. Levels of the different endothelial markers in patients with systemic sclerosis in the discovery cohort: comparison with a population of 20 healthy controls issued from previous publications.

Additional file 3: Figure S1. Representative pictures of the three nailfold videocapillaroscopy (NVC) patterns, as compared with a normal examination. 


\section{Abbreviations}

CEC: circulating endothelial cell; CRP: C-reactive protein; DLCO/AV: diffusing capacity for carbon monoxide/alveolar volume; EPC: endothelial progenitor cell; ESR: erythrocyte sedimentation rate; mRSS: modified Rodnan skin score; NVC: nailfold videocapillaroscopy; PIGF: placenta growth factor; SPAP: systolic pulmonary artery pressure; SSc: systemic sclerosis; sVCAM: soluble vascular cell adhesion molecule; VEGF: vascular endothelial growth factor.

\section{Authors' contributions}

JA participated in the design of the study, performed nailfold videocapillaroscopy, participated to the analysis and interpretation of the data, performed the statistical analysis, and wrote the manuscript. MV performed the EPC/CEC quantification by flow cytometry and ELISA measurement, and collected the clinical data. VS participated in the analysis and interpretation of the data. PS performed nailfold videocapillaroscopy. BR performed the EPC/CEC quantification with flow cytometry and ELISA measurement. AS, CP, CF, GC, and MC participated in the analysis and interpretation of the data. YA conceived the study, participated in its design, participated in the analysis and interpretation of the data, and performed the statistical analysis. All authors drafted, read, and approved the final manuscript.

\section{Competing interests}

Prof. Allanore and Dr. Avouac have received research grants and honoraria from Actelion and Pfizer (less than $\$ 10,000$ USD each). The remaining authors have no competing interest.

\section{Acknowledgements}

This research work was supported by an unrestricted grant from Actelion Pharmaceuticals France.

\section{Author details}

${ }^{1}$ Rheumatology A department, Paris Descartes University, Sorbonne Paris Cité, Cochin Hospital, rue du Faubourg Saint Jacques, 27, Paris, 75014, France. ${ }^{2}$ INSERM U1016 and CNRS UMR8104, Cochin Institute, Paris Descartes University, rue du Faubourg Saint Jacques, 27, Paris, 75014, France. 3 Department of Rheumatology, Ghent University Hospital, De Pintelaan 185, Ghent, 9000 Belgium. ${ }^{4}$ Department of Dermatology, Paris X University, Tenon Hospital, Rue de la Chine, 4, Paris, 75020, France. ${ }^{5}$ Research Laboratory and Academic Unit of Clinical Rheumatology, Department of Internal Medicine, University of Genova, Viale Benedetto XV, 6, Genova, 16132, Italy.

Received: 20 December 2012 Revised: 5 March 2013

Accepted: 9 April 2013 Published: 19 April 2013

\section{References}

1. Allanore Y, Avouac J, Wipff J, Kahan A: New therapeutic strategies in the management of systemic sclerosis. Expert Opin Pharmacother 2007, 8:607-615

2. Sgonc $R$, Gruschwitz MS, Dietrich $H$, Recheis $H$, Gershwin ME, Wick G: Endothelial cell apoptosis is a primary pathogenetic event underlying skin lesions in avian and human scleroderma. J Clin Invest 1996, 98:785-792.

3. Maurer B, Busch N, Jungel A, Pileckyte M, Gay RE, Michel BA, Schett G, Gay S, Distler J, Distler O: Transcription factor fos-related antigen-2 induces progressive peripheral vasculopathy in mice closely resembling human systemic sclerosis. Circulation 2009, 120:2367-2376.

4. Reich N, Maurer B, Akhmetshina A, Venalis P, Dees C, Zerr P, Palumbo K, Zwerina J, Nevskaya T, Gay S, Distler O, Schett G, Distler JH: The transcription factor Fra-2 regulates the production of extracellular matrix in systemic sclerosis. Arthritis Rheum 2010, 62:280-290.

5. Nguyen VA, Sgonc R, Dietrich H, Wick G: Endothelial injury in internal organs of University of California at Davis line 200 (UCD 200) chickens, an animal model for systemic sclerosis (scleroderma). J Autoimmun 2000, 14:143-149.

6. Avouac J, Elhai M, Allanore Y: Experimental models of dermal fibrosis and systemic sclerosis. Joint Bone Spine 2013, 80:23-28.

7. Fleming JN, Nash RA, McLeod DO, Fiorentino DF, Shulman HM, Connolly MK, Molitor JA, Henstorf G, Lafyatis R, Pritchard DK, Adams LD, Furst DE, Schwartz SM: Capillary regeneration in scleroderma: stem cell therapy reverses phenotype? PLOS ONE 2008, 3:e1452.
8. Cutolo M, Sulli A, Pizzorni C, Accardo S: Nailfold videocapillaroscopy assessment of microvascular damage in systemic sclerosis. J Rheumatol 2000, 27:155-160.

9. Cutolo M, Sulli A, Smith V: Evaluating microangiopathy in systemic sclerosis: what have we learnt and what is left to discover? Expert Rev Clin Immunol 2011, 7:395-397.

10. Avouac J, Fransen J, Walker UA, Riccieri V, Smith V, Muller C, Miniati I,

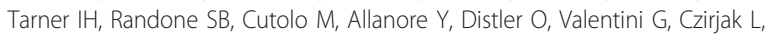
Müller-Ladner U, Furst DE, Tyndall A, Matucci-Cerinic M, EUSTAR Group: Preliminary criteria for the very early diagnosis of systemic sclerosis: results of a Delphi Consensus Study from EULAR Scleroderma Trials and Research Group. Ann Rheum Dis 2011, 70:476-481.

11. Allanore $Y$, Borderie D, Lemarechal $H$, Ekindjian OG, Kahan A: Nifedipine decreases SVCAM-1 concentrations and oxidative stress in systemic sclerosis but does not affect the concentrations of vascular endothelial growth factor or its soluble receptor 1. Arthritis Res Ther 2004, 6 R309-R314.

12. Distler O, Del Rosso A, Giacomelli R, Cipriani P, Conforti ML, Guiducci S, Gay RE, Michel BA, Brühlmann P, Müller-Ladner U, Gay S, Matucci-Cerinic M: Angiogenic and angiostatic factors in systemic sclerosis: increased levels of vascular endothelial growth factor are a feature of the earliest disease stages and are associated with the absence of fingertip ulcers. Arthritis Res 2002, 4:R11.

13. Wipff J, Avouac J, Borderie D, Zerkak D, Lemarechal H, Kahan A, Boileau C, Allanore $Y$ : Disturbed angiogenesis in systemic sclerosis: high levels of soluble endoglin. Rheumatology (Oxford) 2008, 47:972-975.

14. Hummers LK, Hall A, Wigley FM, Simons M: Abnormalities in the regulators of angiogenesis in patients with scleroderma. J Rheumatol 2009, 36:576-582.

15. Avouac J, Juin F, Wipff J, Couraud PO, Chiocchia G, Kahan A, Boileau C, Uzan $G$, Allanore $Y$ : Circulating endothelial progenitor cells in systemic sclerosis: association with disease severity. Ann Rheum Dis 2008, 67:1455-1460.

16. Avouac J, Uzan G, Kahan A, Boileau C, Allanore Y: Endothelial progenitor cells and rheumatic disorders. Joint Bone Spine 2008, 75:131-137.

17. Riccieri V, Stefanantoni K, Vasile M, Macri V, Sciarra I, lannace N, Alessandri C, Valesini G: Abnormal plasma levels of different angiogenic molecules are associated with different clinical manifestations in patients with systemic sclerosis. Clin Exp Rheumatol 2011, 29:S46-S52.

18. Avouac J, Meune C, Ruiz B, Couraud PO, Uzan G, Boileau C, Kahan A, Chiocchia G, Allanore Y: Angiogenic biomarkers predict the occurrence of digital ulcers in systemic sclerosis. Ann Rheum Dis 2012, 71:394-399.

19. Preliminary criteria for the classification of systemic sclerosis (scleroderma). Bull Rheum Dis 1981, 31:1-6.

20. Clements PJ, Lachenbruch PA, Ng SC, Simmons M, Sterz M, Furst DE: Skin score: a semiquantitative measure of cutaneous involvement that improves prediction of prognosis in systemic sclerosis. Arthritis Rheum 1990, 33:1256-1263.

21. Allanore Y, Borderie D, Avouac J, Zerkak D, Meune C, Hachulla E, Mouthon L, Guillevin L, Meyer O, Ekindjian OG, Weber S, Kahan A: High Nterminal pro-brain natriuretic peptide levels and low diffusing capacity for carbon monoxide as independent predictors of the occurrence of precapillary pulmonary arterial hypertension in patients with systemic sclerosis. Arthritis Rheum 2008, 58:284-291.

22. Avouac J, Airò P, Meune C, Beretta L, Dieude P, Caramaschi P, Tiev K, Cappelli S, Diot E, Vacca A, Cracowski JL, Sibilia J, Kahan A, MatucciCerinic $M$, Allanore Y: Prevalence of pulmonary hypertension in systemic sclerosis in European Caucasians and metaanalysis of 5 studies. $J$ Rheumatol 2010, 37:2290-2298.

23. Cutolo M, Nobili F, Sulli A, Pizzorni C, Briata M, Faelli F, Vitali P, Mariani G, Copello F, Seriolo B, Barone C, Rodriguez G: Evidence of cerebral hypoperfusion in scleroderma patients. Rheumatology (Oxford) 2000 39:1366-1373.

24. Sulli A, Secchi ME, Pizzorni C, Cutolo M: Scoring the nailfold microvascular changes during the capillaroscopic analysis in systemic sclerosis patients. Ann Rheum Dis 2008, 67:885-887.

25. Khan SS, Solomon MA, McCoy JP Jr: Detection of circulating endothelial cells and endothelial progenitor cells by flow cytometry. Cytometry B Clin Cytom 2005, 64:1-8.

26. Dziankowska-Bartkowiak B, Waszczykowska E, Dziankowska-Zaboroszczyk E, de Graft-Johnson JE, Zalewska A, Luczynska M, Nowak D: Decreased ratio 
of circulatory vascular endothelial growth factor to endostatin in patients with systemic sclerosis: association with pulmonary involvement. Clin Exp Rheumatol 2006, 24:508-513.

27. Coral-Alvarado P, Quintana G, Garces MF, Cepeda LA, Caminos JE, Rondon F, Iglesias-Gamarra A, Restrepo JF: Potential biomarkers for detecting pulmonary arterial hypertension in patients with systemic sclerosis. Rheumatol Int 2009, 29:1017-1024.

28. Noda S, Asano Y, Aozasa N, Akamata K, Yamada D, Masui Y, Tamaki Z, Kadono T, Sato S: Serum Tie2 levels: clinical association with microangiopathies in patients with systemic sclerosis. J Eur Acad Dermatol Venereol 2011, 25:1476-1479.

29. Jodon de Villeroche V, Avouac J, Ponceau A, Ruiz B, Kahan A, Boileau C, Uzan G, Allanore Y: Enhanced late-outgrowth circulating endothelial progenitor cell levels in rheumatoid arthritis and correlation with disease activity. Arthritis Res Ther 2010, 12:R27.

30. Del Papa N, Quirici N, Soligo D, Scavullo C, Cortiana M, Borsotti C, Maglione W, Comina DP, Vitali C, Fraticelli P, Gabrielli A, Cortelezzi A, Lambertenghi-Deliliers $\mathrm{G}$ : Bone marrow endothelial progenitors are defective in systemic sclerosis. Arthritis Rheum 2006, 54:2605-2615.

31. Del Papa N, Colombo G, Fracchiolla N, Moronetti LM, Ingegnoli F, Maglione W, Comina DP, Vitali C, Fantini F, Cortelezzi A: Circulating endothelial cells as a marker of ongoing vascular disease in systemic sclerosis. Arthritis Rheum 2004, 50:1296-1304.

32. Koch $A E$, Distler $\mathrm{O}$ : Vasculopathy and disordered angiogenesis in selected rheumatic diseases: rheumatoid arthritis and systemic sclerosis. Arthritis Res Ther 2007, 9(Suppl 2):S3.

33. Huang CL, Mutasim DF: Sarcoidosis mimicking lipodermatosclerosis. Cutis 2005, 75:322-324.

34. Kuwana M: Potential benefit of statins for vascular disease in systemic sclerosis. Curr Opin Rheumatol 2006, 18:594-600.

35. Ferri C, Giuggioli D, Sebastiani M, Colaci M: Treatment of severe scleroderma skin ulcers with recombinant human erythropoietin. Clin Exp Dermatol 2007, 32:287-290

36. Choi JJ, Min DJ, Cho ML, Min SY, Kim SJ, Lee SS, Park KS, Seo YI, Kim WU, Park SH, Cho CS: Elevated vascular endothelial growth factor in systemic sclerosis. J Rheumatol 2003, 30:1529-1533.

37. Moneib HA, Salem SA, Aly DG, Khedr HT, Wafaey HA, Hassan HE: Assessment of serum vascular endothelial growth factor and nail fold capillaroscopy changes in systemic lupus erythematosus with and without cutaneous manifestations. J Dermatol 2012, 39:52-57.

38. Distler O, Distler JH, Scheid A, Acker T, Hirth A, Rethage J, Michel BA, Gay RE, Müller-Ladner U, Matucci-Cerinic M, Plate KH, Gassmann M, Gay S: Uncontrolled expression of vascular endothelial growth factor and its receptors leads to insufficient skin angiogenesis in patients with systemic sclerosis. Circ Res 2004, 95:109-116.

39. Caramaschi P, Canestrini S, Martinelli N, Volpe A, Pieropan S, Ferrari M, Bambara LM, Carletto A, Biasi D: Scleroderma patients nailfold videocapillaroscopic patterns are associated with disease subset and disease severity. Rheumatology (Oxford) 2007, 46:1566-1569.

40. Sebastiani M, Manfredi A, Colaci M, D'Amico R, Malagoli V, Giuggioli D, Ferri C: Capillaroscopic skin ulcer risk index: a new prognostic tool for digital skin ulcer development in systemic sclerosis patients. Arthritis Rheum 2009, 61:688-694.

41. Sebastiani M, Manfredi A, Vukatana G, Moscatelli S, Riato L, Bocci M, ludici M, Principato A, Mazzuca S, Del Medico P, De Angelis R, D'Amico R, Vicini R, Colaci M, Ferri C: Predictive role of capillaroscopic skin ulcer risk index in systemic sclerosis: a multicentre validation study. Ann Rheum Dis 2012, 71:67-70

42. Smith V, De Keyser F, Pizzorni C, Van Praet JT, Decuman S, Sulli A, Deschepper E, Cutolo M: Nailfold capillaroscopy for day-to-day clinical use: construction of a simple scoring modality as a clinical prognostic index for digital trophic lesions. Ann Rheum Dis 2011, 70:180-183.

doi:10.1186/ar4217

Cite this article as: Avouac et al:: Correlations between angiogenic factors and capillaroscopic patterns in systemic sclerosis. Arthritis Research \& Therapy 2013 15:R55.

\section{Submit your next manuscript to BioMed Central and take full advantage of:}

- Convenient online submission

- Thorough peer review

- No space constraints or color figure charges

- Immediate publication on acceptance

- Inclusion in PubMed, CAS, Scopus and Google Scholar

- Research which is freely available for redistribution

Submit your manuscript at www.biomedcentral.com/submit
Ciomed Central 